\title{
Imprensa e Escola Normal: representações de progresso e civilização na produção de um imaginário social - 1918-1938*
}

\author{
Geisa Magela Veloso
}

Universidade Estadual de Montes Claros, Centro de Ciências Humanas

\section{Introdução}

Neste artigo discutimos processos pelos quais, em situações cotidianas, sujeitos sociais realizam apropriações de conteúdos em circulação e se inscrevem entre práticas e representações. Representações que não são a realidade, mas encontram-se imbuídas de interesses e significações que integram o processo de informar e formar a opinião pública e têm papel ativo na produção de um ideal de sociedade e na mobilização das ações. Dessa forma, conferimos visibilidade para ocorrências que tiveram lugar em Montes Claros, no Estado de Minas Gerais, nas décadas de 1910-1930, visando a sinalizar para a pertinência de utilização dos conceitos de representação, apropriação e prática

* Este artigo é resultante de pesquisa de doutorado desenvolvida junto ao Programa de Pós-Graduação da Universidade Federal de Minas Gerais (UFMG), com orientação e coorientação das professoras Aparecida Paiva e Cynthia Greive Veiga, e contou com financiamento da Fundação de Amparo à Pesquisa do Estado de Minas Gerais (FAPEMIG).
(Chartier, 1990, 2001, 2002) e de imaginário social (Baczko, 1985), no contexto da história cultural.

Visando atender a esse objetivo, discuto e analiso publicações da Gazeta do Norte, semanário “independente, literário e noticioso" que circulou entre 1918 e 1962 e assumiu missão educativa e civilizatória em relação à população montes-clarense. Em seu empreendimento educativo, o jornal visava a promover o desenvolvimento individual e o progresso da cidade, elegendo a Escola Normal de Montes Claros como referência e inspiração. Por mediações discursivas diferenciadas, identifico as finalidades educativas pretendidas por essas instâncias educativas - jornal e escola -, mas, sobretudo, as representações acerca da educação, da instrução e da alfabetização produzidas pelos sujeitos envolvidos e as apropriações que fizeram dos discursos que circularam nas primeiras décadas do século XX.

Como fontes documentais, utilizei aproximadamente 1.031 exemplares do jornal Gazeta do Norte e outros jornais que circularam em Montes Claros. Para ampliação das possibilidades de compreensão da realidade e reconstituição da memória, considerei ainda 
duas obras produzidas por cidadãos montes-clarenses: monografia de Urbino Vianna (1916) e livros do historiador Hermes de Paula (1957).

Visando captar a sincronia do movimento histórico local em sua relação com o contexto mineiro, utilizei 95 volumes da Revista do Ensino (1925-1933), publicação pedagógica do governo mineiro que se constituiu em importante recurso de divulgação do movimento de renovação do ensino e do projeto de reforma pretendido para as escolas do estado. Criada pelo Regulamento do Ensino, que no artigo 479 indica seu objetivo educativo, a Revista visava a quebrar a resistência dos professores, levando-os à adesão aos novos métodos de ensino. Estava “destinada a orientar, estimular e informar os funccionarios do ensino e os particulares interessados em assumptos com este relacionados” (Minas Gerais, 1925).

Com o estudo pretendo mostrar que, em Montes Claros, o jornal Gazeta do Norte trabalhou para a formação da opinião pública e a educação de seu público leitor, favorecendo a construção e atualização de um imaginário social. Produzindo representações e colocando-as em circulação, o jornal projetou um futuro de progresso e desenvolvimento para a cidade. Por meio de diferentes discursos que circularam em editoriais, crônicas, cartas, termos de visita e inspeção, notícias etc., foram produzidas representações que estabeleceram uma antinomia entre analfabeto-leitor, atrasado-desenvolvido, ignorante-civilizado, visando a mobilizar ações para superação dos problemas e construir um adequado grau de civilização e progresso. Por essas representações, a instrução, a educação e a alfabetização apresentavam-se como resposta ao atraso cultural, aos crimes, à marginalidade, à vadiagem, à deformação dos valores morais e, ao mesmo tempo, como recurso capaz de instaurar o progresso e legitimar a verdadeira cidadania.

Conforme Chartier (1990, 2002), a pertinência operatória de tomar o conceito de representação para tratar de objetos culturais resulta de duas ordens de razões. Em primeiro lugar está o fato de o conceito não ser estranho às sociedades do Antigo Regime, cuja utilização manifesta a tensão entre duas famílias de sentido: a representação dando a ver uma coisa ausente, como a exibição de uma presença, a apresentação pública de algo ou de alguém. A segunda razão para sua utilização é que, mais do que um conceito de mentalidade, as representações permitem articular três modalidades de relações com o mundo social: a) o trabalho de classificação e de delimitação, que produz configurações intelectuais múltiplas, por meio das quais a realidade é contraditoriamente construída; b) as práticas que visam fazer reconhecer uma identidade social, exibir uma maneira própria de estar no mundo, significar simbolicamente um estatuto e uma posição; c) as formas institucionalizadas e objetivadas pelas quais uns "representantes" marcam a existência do grupo, da classe, da comunidade (Chartier, 2002).

Ou seja, pelo processo de representar, os sujeitos sociais fazem investimentos cognitivos, apropriam-se de conteúdos em circulação e criam categorias explicativas para o mundo social. Também produzem práticas cotidianas que demarcam sua posição individual no grupo de pertença, colocando em jogo os sistemas partilhados pelos quais é possível perpetuar e dar visibilidade aos grupos sociais. As representações são práticas de ordenamento do social construídas pelos indivíduos enquanto sujeitos sociais que buscam compreender a realidade na qual estão inseridos e travam relações.

Consideramos, com Barros (2004), que a análise histórica das representações permite compreender que elas encontram-se emaranhadas às ações e práticas, às atitudes e gestos, não sendo possível distinguir onde estão os começos, se em determinadas práticas, se em determinadas representações.

Por essa perspectiva, pretendemos discutir o modo como a produção de representações permite a antevisão de um sucesso futuro, impressiona a imaginação, produz crenças na legitimidade de um projeto, impulsiona ações. Em contrapartida, na medida em que as ações produzem modificações na vida social, são produzidas novas representações e símbolos, que reorientam os sentidos atribuídos ao fazer dos sujeitos coletivos, gerando novas práticas.

Para Baczko (1985), o imaginário social, compreendido como conjunto de representações, é uma 
peça efetiva e eficaz para controlar a vida social e coletiva, sendo também lugar e objeto de conflitos sociais. É no centro do imaginário que se encontra o centro do poder legítimo; as épocas de crise apresentam-se como momentos ideais para intensificar a produção de imaginários concorrentes e antagonistas, em que as representações de uma nova legitimidade e de um futuro diferente proliferam-se e ganham difusão por meio dos símbolos produzidos pelos sujeitos.

Ainda conforme o autor, tais símbolos são construídos pelas experiências dos agentes sociais, mas também por seus desejos, aspirações, motivações, expectativas, esperanças, temores e recusas. Por estarem ancoradas nas necessidades dos indivíduos e dos grupos sociais, as representações tornam-se uma razão de existir. O imaginário informa acerca da realidade e constitui um apelo para a ação, suscita a adesão a um sistema de valores, modelando o comportamento e, em caso de necessidade, arrastando os indivíduos para uma ação comum (Baczko, 1985).

Por essa perspectiva teórica, tornou-se possível compreender que não apenas os objetos culturais são produzidos entre práticas e representações, mas também os sujeitos produtores e receptores de cultura circulam entre esses polos, que correspondem a modos de fazer e modos de pensar. Assim, constatamos que intelectuais montes-clarenses ligados à Escola Normal e ao jornal e investidos do desejo de construir uma cidade moderna e civilizada produziram representações que deram a ver um futuro de progresso para Montes Claros. Em nossa análise, para além dos sujeitos sociais e das agências nas quais exerceram seu ofício, tornou-se possível compreender a apropriação dos conteúdos em circulação, as práticas colocadas em curso e os processos de produção da cultura.

\section{O movimento estratégico do jornal Gazeta do Norte e sua relação com a Escola Normal de Montes Claros}

Nas décadas de 1910-1930, a Gazeta do Norte, instalada no ano de 1918 por José Thomaz de Oliveira, trabalhou intensamente na produção de repre- sentações que colocaram a instrução, a educação e a alfabetização como condições para Montes Claros conquistar status de cidade evoluída e civilizada. Vale destacar que a cidade havia sido emancipada em 1857 e, conforme Paula (1957), contava com 4.193 habitantes em 1913; a instalação da energia elétrica ocorreu somente em 1917 e o abastecimento de água canalizada, em 1938. Afastada da capital mineira por $420 \mathrm{~km}$ de estradas praticamente inexistentes, o primeiro caminhão chegou à cidade em 1920, e a estrada de ferro, em 1926. Os jornais locais não tinham vida longa, abriam-se e fechavam com muita frequência, e a primeira rádio comercial foi instalada somente em 1944, a ZYD-7, Rádio Sociedade Norte de Minas. A Escola Normal Oficial foi criada em 1878, ainda no governo provincial, sendo extinta em 1905 e reaberta em 1915, por iniciativa do coronel João de Andrade Câmara, como escola livre.

Apesar das dificuldades, nas décadas de 1910-1930 a cidade de Montes Claros esteve envolvida em intensa produção cultural. Por isso, procuramos entender o encontro de interesses da Gazeta do Norte e da Escola Normal, instituições que assumiram a missão de educar os cidadãos e modernizar a cidade e encontravam-se imbricadas: comungavam ideal civilizatório e compartilhavam quadro militante - intelectuais com funções dirigentes e docentes na Escola eram também redatores, diretores e colaboradores do jornal. Ao fazerem apropriação de modelos culturais, esses intelectuais desenvolveram práticas, produziram representações e as fizeram circular visando à mudança de mentalidade e a conformação de novos comportamentos.

Inspirada em Certeau (1999), entendo que a associação da Gazeta do Norte com a Escola Normal afigurou-se como movimento estratégico, ainda que não tenha sido intencionalmente planejado, por antever a possibilidade de auferir lucros com o fato. É provável que a percepção da rentabilidade social dessa associação tenha sido construída no decurso do tempo, a partir da adesão dos montes-clarenses à Escola e dos investimentos que a cidade fazia para sua consolidação.

Ao recrutar seus colaboradores entre os integrantes da elite cultural local, o jornal pretendia ga- 
rantir credibilidade junto aos leitores. E, dessa forma, professores e outros detentores de diplomas de nível superior, pessoas de prestígio e reconhecimento junto à comunidade, passaram a fornecer conteúdo para as publicações. Contudo, esse não era o único vínculo que unia as duas instituições. O jornal dependia da escolarização para ampliar o quadro de leitores e consolidar seu lugar como empresa de comunicação. No entanto, por um cálculo estratégico, apresentava a si mesma como instituição guiada por objetivos e práticas desinteressadas. Adotando os projetos de civilização e progresso da cidade, o jornal e seu proprietário obtiveram adesão dos montes-clarenses, encontraram espaço de atuação e, na acepção de Certeau (1999), construíram um lugar próprio e inscreveram-se no mundo de poder do outro.

Por sua vez, a Escola Normal também obteve benefícios de sua relação com a Gazeta do Norte que lhe conferiram visibilidade e prestígio, apoiaram suas iniciativas, defenderam seus interesses, ampliaram a capacidade de disseminar conhecimentos e de fazer ouvida a voz dos intelectuais. Dessa forma, podemos compreender essa rede de relações. Mobilizados por objetivos comuns, escola e jornal desenvolveram uma série de ações e, em nome do progresso e da civilização, também trabalharam para garantir sua existência institucional.

Nesse contexto, assumindo-se como artífices da modernidade e da civilização, os intelectuais ligados à escola desenvolveram atividade militante na Gazeta do Norte. Elegendo a educação e a alfabetização como símbolos do progresso idealizado, a Escola Normal tornou-se referência e inspiração para a produção de diferentes representações, imagens e significações, integrando o imaginário social e mobilizando ações.

Ao conferir visibilidade à Escola Normal e publicar palestras, conferências, artigos pedagógicos e matérias que produziram a educação como notícia, a Gazeta do Norte fabricou um imaginário social pelo qual pretendia provocar mudanças no conjunto de ideias, valores e crenças de sua época, nos modos de pensar a realidade e nos saberes que orientavam as formas de organização da vida.
Com Chartier (1990), entendo que a produção de representações não é um processo neutro e desinteressado, mas marcado pelas posições e intenções daqueles que as produzem; que as percepções do mundo social não são discursos neutros, pois delas são originadas estratégias e práticas que tendem a impor uma autoridade, legitimar um projeto reformador, justificar escolhas e condutas. Dessa forma, por sua não-neutralidade, a Gazeta do Norte disseminava representações visando a impressionar a imaginação e a mobilizar as ações em favor da manutenção da Escola Normal, compreendida como fator de desenvolvimento e civilização.

Em outras palavras, apoiar a Escola Normal não era ação desinteressada, mas parte do movimento estratégico empreendido pela Gazeta do Norte, cuja sobrevivência como empresa jornalística dependia de sua inserção na cidade, de sua aceitação pela comunidade local e da ampliação de uma comunidade de leitores. Assim, nessa via de mão dupla, o jornal alimentavase de publicações originadas da Escola Normal e, ao mesmo tempo, dava suporte ao seu funcionamento, apoiando suas realizações e chamando a comunidade para participar. E, para a escola, esse apoio tornou-se imprescindível.

Afinal, a trajetória da Escola Normal de Montes Claros é bastante irregular, marcada por sucessivas extinções e reaberturas; os historiadores montesclarenses consideram seu percurso constituído por três fases. Ao analisar essa trajetória, percebo a emergência de distintas escolas, para as quais se construíram laços de interdependência; mesmo assim, os interesses locais compreendem-na como uma única instituição - “a nossa escola normal”, ainda hoje presente no imaginário da cidade.

A primeira fase da Escola Normal compreende o intervalo entre 1878 e 1905, que delimita o ano de sua criação como escola oficial, ainda no período imperial, e o de sua extinção por decreto do governo mineiro. A segunda fase circunscreve-se entre 1915 e 1938, período delimitado por sua fundação como escola livre e sua extinção como escola oficial, e inclui a desativação em 1918, a reabertura em 1923, a equiparação às escolas oficiais de Minas em 1925 
e o encampamento pelo poder público estadual em 1928. A terceira fase tem início em 1953, quando foi reaberta como escola oficial, e se prolonga até o momento atual, em que funciona como escola regular de educação básica.

Após a sua primeira extinção, em 1905, transcorreram dez anos para que Montes Claros voltasse a ter uma escola de formação de professores, o que somente ocorreu por iniciativa do coronel João de Andrade Câmara, em 1915. Fundada como Escola Normal livre, a instituição enfrentou dificuldades para garantir seu funcionamento nos primeiros anos de atividade, não apenas para financiar o empreendimento, mas também porque muitos montes-clarenses não acreditavam ser possível manter a escola por iniciativa particular. Em 1916, em solenidade de comemoração de seu $1^{\circ}$ aniversário, o diretor Antônio Olyntho Martins expressou seu desconforto diante dos pessimistas e confessou: "senti-me desfalecer por muitas vezes ante a descrença de uns e o desânimo de outros” (JMC, 29, 1916)1.

O desânimo e a descrença aludidos encontravam justificativa na própria irregularidade da Escola. Nesse sentido, o apoio da Gazeta do Norte foi importante, por produzir representações positivas associadas à educação e aos benefícios advindos da alfabetização, favorecendo o rompimento de resistências e a adesão da comunidade. Ao construir uma visão otimista e bem-sucedida, capaz de impressionar a imaginação e produzir credibilidade, o jornal impulsionava ações e impedia que a descrença se generalizasse e imobilizasse a população. Assim, fez crer na ideia de que a atuação da Escola Normal resultaria na construção de uma cidade civilizada, com “a instrucção clariando

${ }^{1}$ Visando facilitar o ritmo da leitura, a indicação das fontes documentais citadas será registrada com as letras iniciais dos nomes dos jornais, seguidas do número do volume e o ano de sua publicação. Dessa forma, JMC significa Jornal Montes Claros, GN indica o jornal Gazeta do Norte e $O P$ abrevia o nome do jornal $O$ Operário. Os dois primeiros encontram-se arquivados no Centro de Pesquisa e Documentação da Unimontes, em Montes Claros, e o último encontra-se na Hemeroteca Assis Chateaubriand, em Belo Horizonte. os espíritos, cultivando intelligencias, preparando os homens de amanhã” (GN, 673, 1929).

Dessa forma, com a produção de representações positivas, a Gazeta do Norte marcou presença, demarcou seu espaço e definiu seu lugar de poder. Sempre apoiando as iniciativas da Escola Normal, divulgando suas realizações e estimulando a adesão da comunidade, o jornal trabalhou pelo projeto de civilização e progresso. Na esteira de suas publicações, foi possível perceber o aspecto noticioso, mas sobretudo a faceta educativa e formadora do jornal. As notícias não pretendiam meramente dar a ver os fatos, mas legitimar determinadas práticas, modelar comportamentos, formar a opinião pública, consolidar a Escola Normal. Ao transformar os fatos educativos em notícia, o jornal revela seu interesse em conferir visibilidade à educação e legitimar a Escola Normal como instância de desenvolvimento da região. As honrarias e homenagens que o jornal prestou aos moradores e visitantes “ilustres” igualmente dão a ver esse ideal formador, indicando um olhar de aprovação lançado sobre o civilizado, o culto, o moderno e o avançado.

Por essa perspectiva, a Gazeta do Norte tornou-se lugar da opinião pública, produzindo representações, selecionando temáticas, fazendo circular ideias e colocando as pessoas em comunicação. No entanto, o jornal também se vinculou às sociabilidades e práticas, aos comportamentos e às formas concretas de viver em sociedade. E a Escola Normal fez parte desse processo, sendo igualmente um lugar da opinião pública e uma instância guardiã da civilização.

\section{O jornal Gazeta do Norte e a produção de um imaginário social}

Por ideais e interesses comuns, Gazeta do Norte e Escola Normal produzem-se como instituições interdependentes, construindo uma história que se entrelaça e dialoga com o desenvolvimento da cidade. Na segunda fase de funcionamento da Escola Normal (1915-1938), o jornal acompanhou de perto as irregularidades de seu funcionamento, construindo-a como notícia e conferindo-lhe visibilidade. Em 1918, 
anunciou o encerramento dos trabalhos escolares, acatando o decreto n. 5133, de 17 de dezembro de 1918, que adiava a época dos exames e matrículas em função de epidemia de gripe espanhola ( $G N, 26$, 1918). Em 1919, ressaltou a não-reabertura da escola, quando a epidemia já estava sob controle e as demais escolas locais retomaram suas atividades letivas ( $G N$, 31, 1919). Na época, o jornal apontou os prejuízos causados pela desativação da Escola, que encerrou atividades sem ter diplomado nenhuma normalista (GN, 44, 1919). Ao alertar os montes-clarenses para os cuidados necessários à reorganização do funcionamento da Escola, evitando “as injustiças, preferições e favores” (GN, 67, 1919), o jornal discutiu as razões que motivaram sua não-reabertura. Nessa ocasião, ainda em 1919, a Gazeta do Norte indicava a má direção da escola como motivo que justificou seu fechamento (GN, 67, 1919). Contudo, em 1921, o jornal passou a considerar que o desânimo provocado pelo impedimento legal de equiparação da instituição com as escolas oficiais mineiras tenha sido o problema que interrompeu precocemente as atividades de formação de normalistas (GN, 134, 1921).

Em 1920, em apoio ao movimento de reorganização da Escola Normal, a Gazeta do Norte destacou apelo do seu professor-fundador, o coronel João de Andrade Câmara, que solicitava aos montes-clarenses que "envidem todos os esforços para a manutenção da Escola Normal e para que a municipalidade consiga edificar um prédio para seus trabalhos" (GN, 110, 1920). Em 1921, o jornal anunciou a chegada do professor Matheus Alves Pereira, inspetor regional indicado para organizar a escola, "que tem arrastado vida inglória desde que de sua direcção foi affastado, por motivos de mudança, o Dr. Olyntho Martins” (GN, 134, 1921). Em 1923, o jornal anunciou a reabertura da extinta escola ( $G N, 245,1923)$, divulgou os exames de admissão e a solenidade de reinício das aulas (GN, 252, 1923). Em 1924, acompanhou as ações para equiparação da escola às oficiais do Estado (GN, 297, 1924) e noticiou a fiscalização que visava a esse intento (GN, 302, 1920). Em 1925, ainda com o intuito de dar visibilidade à Escola Normal, o jornal anun- ciou a "effusão de contentamento e de gratidão” dos montes-clarenses pelo ato de equiparação da Escola Normal às oficiais do Estado ( $G N, 340,1925)$. No ano seguinte, passou a discutir a possibilidade de seu encampamento pelo governo mineiro, visando tornála uma instituição oficial (GN, 419, 1926). Também anunciou sua oficialização no ano de 1928 (GN, 608, 1928) e a implantação do Curso de Aplicação, em 1935 (GN, 957, 1935).

Enfim, a Gazeta do Norte funcionou como uma espécie de porta-voz da Escola Normal, exercendo uma função crucial para sua integração ao imaginário local e para o processo de sua consolidação como instituição formadora de professores. Isso porque, na medida em que as pessoas construíam a crença na possibilidade de uma Escola Normal atuante e bemsucedida, passavam a defendê-la e a lutar por ela. Por processo similar, na medida em que trabalhava pela escola, a comunidade passava a crer na possibilidade de sua existência e legitimidade. Em outras palavras, as representações geram práticas e as práticas geram representações, conforme afirma Chartier (1990).

Nessa linha de raciocínio, Baczko (1985) compreende que a produção de um imaginário social (conjunto de representações do mundo social) se constitui como móvel da história, uma vez que os sujeitos sociais imaginam percursos para si próprios e essa imaginação apresenta funções reais, por ser capaz de produzir ações. Isso porque, conforme o autor, a faculdade humana de produzir sonhos, ilusões e símbolos é uma condição para a ação dos sujeitos.

Por essa visão, compreendo que a Gazeta do Norte visava a integrar a Escola Normal ao imaginário social por meio da produção de imagens e símbolos que acenavam para um futuro de progresso para Montes Claros e atrelavam esse progresso à educação da população. Se a produção de representações é vista como uma operação realizada por pessoas inseridas em um universo de relações sociais, podemos afirmar que João de Andrade Câmara, fundador da Escola Normal em 1915, e os demais montes-clarenses que contribuíram com o feito, ao empreender suas ações, vislumbravam o social. Por isso, a Gazeta do Norte 
insistia em divulgar a fundação e a manutenção da Escola como ação altruística; as representações que construiu em torno dos intelectuais montes-clarenses revelam pessoas devotadas a Montes Claros e à causa da educação, que realizavam atividade desinteressada, voltada para os interesses coletivos.

Por uma dupla construção simbólica - a de Montes Claros como cidade moderna e a da Escola Normal como símbolo de modernidade -, os intelectuais montes-clarenses protagonizaram a produção de representações de civilização e progresso, projetando uma imagem de futuro que impulsionava ações e pretendia mobilizar a comunidade.

Essa estratégia pode ser compreendida a partir das teorizações de Baczko, ao considerar que um imaginário é capaz de produzir ações, modelar comportamentos, mobilizar energias e legitimar ações dos sujeitos. Assim, é difícil separar os agentes e seus atos das imagens que têm de si próprios e dos inimigos; afinal, "os imaginários operam ainda mais vigorosamente, talvez, na produção de visões futuras, designadamente na projecção das angústias, esperanças e sonhos colectivos sobre o futuro" (Baczko, 1985, p. 312). Ou seja, o autor considera que, por meio de imaginários sociais, uma coletividade designa a sua identidade, elabora certa representação de si, estabelece a distribuição de papéis e posições sociais, constrói uma espécie de código do "bom comportamento" e instala modelos formadores.

Em Montes Claros, pareceu-me difícil isolar os sujeitos e suas ações das representações que produziram. De um lado, imagens de um futuro de progresso e desenvolvimento que tinham por símbolo a instrução e a educação tornavam a Escola Normal uma necessidade. Por outro lado, imagens que atribuíam um valor para a Escola Normal reiteravam o sucesso da antiga, condenavam a iniquidade da medida que a extinguiu em 1905 e afirmavam a necessidade de voltar a atenção para a instituição que renascia.

A organização do imaginário social e a produção das representações eram orientadas pela Gazeta do Norte, que reiterava a necessidade de "desanalfabetizar” a população e colocava a Escola Normal como um dos pilares para isso. Na distribuição dos papéis sociais, como professores fundadores da escola e colaboradores do jornal, coube aos intelectuais a função de dirigir os destinos do povo. A Escola Normal formaria novos professores para disseminar os conhecimentos da ciência. Aos cidadãos caberiam tarefas diferenciadas: adotariam modelos de comportamentos civilizados, apoiariam a escola, matriculariam seus filhos, buscariam a instrução, enquanto o poder público criaria condições para o funcionamento das escolas e atendimento educacional.

Ao referir-se à Escola Normal, visando formar a opinião e obter a adesão da população, o jornal orientava-se por uma tríplice perspectiva. De um lado, os discursos reportavam-se à extinta escola, conferindo-lhe destaque e distinção, lembrando os prejuízos provocados por seu fechamento em 1905. Por outro, colocando o foco no presente, destacavam o relevante papel da escola para a formação intelectual da mocidade, enalteciam a competência e brilhantismo da direção, o trabalho dedicado e abnegado dos professores, o esforço e a disciplina dos alunos, o altruísmo de um grupo de pessoas que fundaram a escola e lutavam por sua manutenção. E tudo isso visava à construção do futuro grandioso da cidade de Montes Claros.

Por produzir a Escola Normal como empreendimento coletivo, o jornal conferia destaque aos intelectuais e reiterava o apelo endereçado à comunidade. Em relação à população, a imagem produzida pela Gazeta do Norte era de pessoas fortes e trabalhadoras; nesse sentido, o apoio à manutenção da Escola Normal era compreendido como consequência natural desse espírito aguerrido. Com base na ideia de que o montesclarense não se acomodava à espera dos governos, o jornal sempre dirigia apelos aos cidadãos, concebidos como pessoas lutadoras, que agiam pela coletividade e progresso da cidade. Ao discutir a reabertura da escola, em 1923, a Gazeta do Norte, "applaudindo a idea” dessa reorganização, destacou não ser "demais todos os esforços que nesse sentido se fizerem" (GN, 245, 1923), pois "Montes Claros ressentia-se da falta de um estabelecimento de instrucção dessa natureza" (GN, 249, 1923). 
Assim, "são todos chamados a cooperar na grande obra da Educação”. E os argumentos para o apelo inscreviam-se na própria natureza da ação, pois “nenhuma outra [obra] se avantaja em valor e méritos” e "nenhum patriota de verdade que se interesse vivamente pela elevação do nível intellectual, moral e cívico do Norte de Minas poderá recusar-lhe o concurso de sua bôa vontade e efficiente appoio" (GN, 248, 1923). E mais, o jornal considerava que todos deveriam auxiliar o diretor Cícero Pereira, "a fim de que possa essa Escola realizar uma de nossas aspirações - distribuir o ensino secundário a dezenas de patrícios, ansiosos por instrucção" (GN, 249, 1923).

$\mathrm{O}$ discurso dirigido às famílias visava obter adesão à causa educacional, constituindo-se como chamamento para matrícula: "mandae pressurosos os vossos filhinhos banharem-se na luz divina que jorra do Sol da Educação" (GN, 248, 1923). Ao emitir convite para participarem da Associação de Pais e Professores, o jornal considerava que, "para esse desideratum é mister apenas que aquelles que se alistarem nessa cruzada sejam convictos e dispostos a auxiliar a idéa de fecundos resultados para Montes Claros” (GN, 254, 1923). Contudo, para as famílias omissas, o discurso era de cobrança: "que se obriguem os paes ignorantes dos seus deveres, a cumpril-os e teremos para o futuro a remodelação da nossa sociedade” (GN, 33, 1919).

Ao conferir publicidade à solenidade de reinstalação da Escola Normal, a Gazeta do Norte considerava que o fato era um atestado da estima dos montes-clarenses pelo empreendimento, "levado a effeito por um núcleo de pessoas interessadas em dotar nossa cidade de um estabelecimento dessa natureza, cuja necessidade todos são unânimes em proclamar”. Ao comentar a solenidade, destacou o apoio da elite local, que em "numerosa e selecta assistência enchia litteralmente todos os ângulos do vasto salão" (GN, 249, 1923).

Ao discutir o encampamento da Escola Normal, a Gazeta do Norte aplaudiu o governo mineiro pela iniciativa de sua oficialização, sobretudo por utilizarse de "critério justo e bem orientado”, "galardeando o esforço e desinteresse daquelles que em outras épocas, com sacrifícios, tomaram a si a tarefa, nobre e altruística de ministrar a instrucção a nossos jovens conterrâneos" (GN, 610, 1928).

A reiteração desses discursos visava reforçar uma imagem, imprimir um desejo de progresso, fazer crer no potencial transformador da instrução, afirmar a necessidade da Escola Normal. Conforme discurso do professor Plínio Ribeiro, diretor interino da Escola Normal em 1933-1934, a instituição era peça fundamental no projeto de civilização. Em suas palavras, a Escola Normal "tem feito infinitamente mais pelo desenvolvimento econômico, material, moral e intellectual deste município e mesmo de todos os demais municípios deste setentrião mineiro que todos os governos passados” (GN, 910, 1934).

Por esse movimento estratégico, a imaginação social construída em torno da Escola Normal era alimentada e orientada nos momentos em que se fazia necessário legitimar a instituição e obter a adesão de todos. Conforme Nascimento (1989), a força da opinião não provém dos intelectuais que a produzem, mas de sua aceitação e assimilação pelo público. Por essa compreensão, quando um intelectual consegue fazer com que suas idéias sejam partilhadas pelo povo, ele consegue resposta ao seu apelo e não estará mais sozinho (Nascimento, 1989). Ou seja, a produção de um imaginário social somente faz sentido quando as representações encontram ressonância junto ao povo, quando as ideias e imagens disseminadas se integram ao seu conhecimento, provocam mudanças em sua maneira de pensar e sentir e orientam suas ações.

Ainda visando à adesão da comunidade, no discurso dos intelectuais, a Escola Normal passou a constituir-se como direito dos montes-clarenses “direito usurpado”, que precisava ser restabelecido, como forma de também reestabelecer uma história de progresso que havia sido interrompida em 1905 (GN, 547, 1927). Por essa lógica, a equiparação da escola com as oficiais do estado, em 1925, foi compreendida como conversão de desejo em realidade, pois a Escola era "a grande, a legítima aspiração dos montesclarenses” (GN, 340, 1925). Pela mesma lógica, em 1928, o seu encampamento pelo governo mineiro era 
mais do que desejo, constituía-se em "um velho e justo objectivo", como a "reparação de uma injustiça” (GN, 608, 1928), na restauração de “direitos postergados há muitos annos com graves damnos” (GN, 547, 1927). Era, portanto, dever do Estado.

Assim, o discurso do direito usurpado e da injustiça cometida contra Montes Claros era tão marcante que, aos poucos, a Gazeta do Norte produziu laços de continuidade entre a antiga e a nova Escola Normal que elas passaram a ser consideradas uma única instituição. "Hoje official, hontem simplesmente equiparada e antes Escola Livre, cujas raízes remotas se prendem à antiga Escola Normal de Montes Claros”(GN, 910, 1934). Nas palavras do jornal, "ela tem passado, tradição, alma, vida” (GN, 945, 1935). Por esses laços produzidos, a trajetória da antiga escola extinta une-se à escola livre criada em 1915, por um processo em que distintas histórias se cruzaram e se completaram, passando a representar a continuidade. Em diferentes momentos, mas, sobretudo, nos de reivindicação, esse imaginário foi alimentado, fazendo crer não apenas no sucesso e na glória de outrora, mas também no sucesso presente e nas promessas para o futuro.

Em 1918, ao apresentar Montes Claros como cidade merecedora de uma Escola Normal oficial, em suas Cartas Semanaes, Honor Sarmento destacou a "reputação inesquecível" e o "magnífico prédio em que já funccionou a antiga Escola Normal” (GN, 10, 1918). Em 1923, em solenidade de reabertura da Escola Normal, o seu diretor, Cícero Pereira, numa referência saudosista à extinta escola oficial, pronunciou-se nos seguintes termos: "são os bons e antigos tempos que se approximam, que voltam. É a renascença áurea dos magníficos tempos de animação, luz e vida. É a belleza da estação floral que retorna" (GN, 248, 1923). Ainda em 1923, ao queixar-se da falta de investimentos públicos na área educacional, o diretor confirmava: "até hoje, [Montes Claros] vive, nesse particular, do conceito e dos resultados da correcção com que se houveram os que dirigiram sua Escola Normal, reputada em todo o estado" (GN, 274, 1923).

Em 1927, ao reivindicar a oficialização da Escola Normal, a Gazeta do Norte conferiu destaque à extinta instituição. Retomando discurso do deputado Alberto Alvares, pronunciado na Assembleia Mineira em 1911, o professor João de Andrade Câmara lembrou que a extinta Escola Normal foi "sempre considerada como um dos mais importantes estabelecimentos officiaes de educação profissional', com “assignalados serviços” prestados à causa do ensino, em cujos anais ficaram registradas "as tradições mais honrosas” (GN, 562, 1927). Já o inspetor regional, Jazon de Moraes, reportando-se à sua extinção em 1905, destacou os "desastrosos effeitos da medida iníqua”, que surpreendeu a todos e restringiu as aspirações educativas das famílias "desprovidas de fortuna” (GN, 547, 1927).

Em 1928, a imagem da escola, "reputada das melhores do Estado” (GN, 608, 1928), foi retomada para reafirmar a legitimidade do encampamento da “nossa escola normal” pelo Estado de Minas. Ou seja, nos projetos de futuro da cidade, essa nova Escola Normal oficial significava o moderno, o progresso, o desenvolvimento. E, no imaginário social, o passado não representava ameaça. Ao contrário, o par antigo/ moderno amalgamava-se e o passado era tomado por uma perspectiva positiva, como prática bem-sucedida e experiência que conferia base para o empreendimento. Com a oficialização da instituição, nascia a certeza de que Montes Claros voltaria a possuir uma escola com a "fama justa de ser uma das melhores do estado, como em outros tempos” (GN, 610, 1928).

Esse modo pelo qual os montes-clarenses valorizavam as experiências anteriores pode ser compreendido a partir de teorizações de Le Goff (2003). Conforme o autor, apesar da disputa entre o novo e o velho, no Ocidente os dois conceitos nem sempre se opuseram e qualquer dos termos pode ser acompanhado de conotações laudatórias, pejorativas ou neutras. Isso porque "novo" implica a ideia de nascimento, de começo, de recém-aparecido. No entanto, “antigo” não pode ser compreendido em termos negativos, uma vez que nas sociedades arcaicas os idosos estavam ligados à sabedoria e à experiência. Para o autor, o antagonismo antigo/moderno, no contexto ocidental, situa-se fundamentalmente no nível cultural, em que os "an- 
tigos” defendem a tradição, enquanto os "modernos” pronunciam-se pela inovação (Le Goff, 2003).

Enfim, por um movimento estratégico e de mútuos interesses, a Gazeta do Norte e a Escola Normal estabeleceram uma interessante parceria, que contribuiu para legitimar o jornal e favoreceu a consolidação da Escola Normal como instituição educadora da mocidade e formadora de professores para a cidade e região.

\section{Imagens e símbolos que produzem o sucesso da Escola Normal}

Na Gazeta do Norte, as imagens que associavam a Escola Normal à “elevação cultural da mocidade” e ao progresso da cidade eram reiteradas em momentos estratégicos, sendo mesmo possível que a força dessas imagens tenha sido maior do que a real notoriedade e a distinção conquistadas pela escola.

Em nossa análise não temos a intenção de colocar em questão essa distinção da escola, mas demonstrar que a retomada dessa imagem bem-sucedida fez parte de um movimento estratégico utilizado pela Gazeta do Norte. Inicialmente, essas imagens e símbolos de sucesso, associados à antiga e à nova Escola Normal, visavam sua manutenção, quebrando as resistências e a descrença daqueles que não acreditavam no empreendimento. Posteriormente, com a equiparação em 1925 e oficialização em 1928, a presença constante da escola no jornal visava consolidar sua credibilidade e produzir consensos acerca de sua eficiência como instituição formadora e sua importância para Montes Claros. Nesse sentido, a Escola passou a ser identificada como "a nossa escola normal”, a "nossa principal casa de instrucção” (GN, 893, 1933), o "nosso principal estabelecimento de instrucção” (GN, 905, 1934).

Para Baczko, o dispositivo imaginário é capaz de suscitar a adesão a um sistema de valores e intervir nos processos de sua interiorização pelos indivíduos, modelando o comportamento e induzindo à ação. Isso porque “o imaginário social informa acerca da realidade, ao mesmo tempo que constitui um apelo à acção, um apelo a comportar-se de determinada maneira” (1985, p. 311).
Nesse sentido, ao entrelaçar a história da extinta escola oficial de formação de professores com a trajetória da instituição que lhe era contemporânea, a Gazeta do Norte produziu a Escola Normal como "a nossa escola”, induzindo a comunidade a reconhecer o seu pertencimento ao patrimônio da cidade. Ao conferir visibilidade aos eventos realizados pela Escola, produzia imagens sempre positivas, eficientes, qualificadas. As festas grandiosas, como as solenidades de formatura, as homenagens, as honrarias e celebrações cívicas eram divulgadas e visavam impressionar a imaginação e dar a ver a importância da escola. Esses eventos eram verdadeiras peças de encenação, que ressaltavam o valor da Escola e procuravam demarcar o papel da educação e da instrução na instauração da modernidade. Essa grandiosidade foi reiterada pelos termos de visita e de inspeção técnica, e a sua divulgação pela imprensa servia de propaganda e cumpria um papel de consolidação do sistema de representações.

Ao falar da Escola Normal, a Gazeta do Norte produziu uma simbologia que a compreendia como: um "grande foco de luz que se accende, mais um santuário que se abre”, como "arvore bem-fazeja e bemdita da Educação popular” (GN, 248, 1923), “pharol da nobre gente nortista” (GN, 922, 1934), "atalaia da ciência” (GN, 946, 1935). E mais: a escola tinha um "brilhante grau de destaque" ( $G N, 870,1933)$, era um "fecundo centro de instrucção e trabalho" (GN, 868, 1933), um "ninho de trabalho e dynamismo", uma “casa de ensino e carinho” (GN, 966, 1935), que apresentava a "maxima ordem e methodo, não só quanto ao ensino, que obedece integralmente às mais modernas leis da pedagogia” (GN, 754, 1931). A escola podia ser considerada "modelo de direcção, pedindo meças as melhores do Estado" (GN, 871, 1933), como lugar que emanava "raios nitentes”, "pejados de luz Divina” (GN, 922, 1934), que os alunos frequentavam para poderem "beber as luzes da instrucção e se preparar para serem os educadores do futuro” (GN, 340, 1925).

Nas representações produzidas pelo jornal, “a Escola Normal de Montes Claros é hoje, no sertão mineiro, um esplendente símbolo das mais altas virtu- 
des do espírito humano", "representa a soma enorme de esforços que, atraves de 25 anos um povo desenvolveu” (GN, 946, 1935). E mais, era “o coroamento natural do zelo da cidade em conservar por tantos annos o patrimônio cultural que tanto a dignifica e enriquece” (GN, 948, 1935). Por seu trabalho, a Escola constituiu-se como "viveiro irradiador de instrucção e sociabilidade” (GN, 966, 1935), capaz de “divulgar o que há de mais útil e interessante na moderna ciência de educar" ( $G N, 975,1935)$. Para a cidade de Montes Claros, a escola era um "laboratório de idéas”, “elemento propulsor maximo de seu progresso e da sua formação moral” (GN, 910, 1934).

A Escola Normal "se harmoniza com a grande organização educacional do Universo" e, "se abrirmos os sentidos e ao misterioso mundo das vibrações espirituais poderemos ouvir, naquele vetusto casarão, a sinfonia do trabalho e do amor”. Também era possível perceber o "ambiente de harmonia e de ordem, de boa vontade e ajuda-mutua” (GN, 946, 1935), “ambiente de trabalho, alegria e cooperação” (GN, 966, 1935), e sentir-se acolhido pela "sombra protectora deste velho tecto acolhedor e amigo” (GN, 948, 1935). Em relação às instalações físicas, as descrições eram feitas em termos mais modestos. A escola estava "installada em predio antigo, porém amplo, confortavel e com todos os requisitos de hygiene" (GN, 754, 1931); "prédio vasto, dos melhores da cidade” (GN, 608, 1928).

Por essa mesma lógica, a cidade era compreendida como lugar evoluído, e o desejo manifesto pela Gazeta do Norte era que "a nossa querida Montes Claros continue a gozar com vantagem da justa fama de cidade culta, grande, à altura da grandeza do seu Estado” (GN, 340, 1925). Como “cidade dynamo, Montes Claros é synonimo de trabalho, de esforço e persistência”. E o ensino ofertado pela escola atendia às necessidades e demandas, porque "Montes Claros em educação como em outros problemas tem tomado sempre um rumo novo e profícuo” (GN, 922, 1934).

E esse "rumo novo e profícuo" era produzido pela ação de todos aqueles que faziam o dia a dia da escola: professores, alunos e direção. Para o jornal, a Escola Normal contava com o privilégio de possuir um “corpo docente escolhido e capaz, onde se preparam as obreiras para a educação d'amanhã” (GN, 673, 1929).

Não apenas na Gazeta do Norte, mas também no jornal $O$ Operário, eram bastante generosos os adjetivos que qualificavam e descreviam o corpo docente, que "além de culto é de uma grande capacidade de organização e trabalho, para maior eficiência do desdobramento cultural da escola” $(O P, 105,1932)$, “fazendo desta casa não um recinto de tédio, mas, tão somente, um núcleo de sociabilidade para a mocidade montes-clarense” (GN, 673, 1929). Os professores eram compreendidos como pessoas que "se esforçam no sentido de que ella [a escola] corresponda plenamente às necessidades da vasta zona que beneficia" (GN, 754, 1931). "Graças à sua elevada cultura e incontestável devotamento” (GN, 946, 1935), e também à sua "acção efficiente" e os "modernos processos de ensinar” (GN, 966, 1935), na Escola Normal a “actividade didática se vem desenvolvendo no sentido de encaminhar a mocidade ao estudo meditado dos melhores autores e scientistas" (GN, 972, 1935).

Nesse mesmo sentido, que exaltava a eficiência profissional e as qualidades pessoais na Gazeta do Norte, as palavras que qualificavam os diretores da Escola eram bastante positivas. O professor Luiz Gonzaga Júnior era o “digno e illustre director” (GN, 642, 1928), “de visão tão clara e percepção tão fácil que sabia transformar, com rapidez, em razão criteriosa as emoções de um povo simples” (GN, 655, 1929). O professor Almir de Souza era "um verdadeiro orientador e amigo - simples e enérgico, bondoso e competente" (GN, 674, 1929), "exerceu o cargo de diretor com competência e critério” (GN, 663, 1929).

O jornal não poupou elogios ao trabalho e à pessoa de Francisco Floriano de Paula, "revelado sobejamente digno do encargo que lhe foi confiado pelo governo. Espírito culto e reformador, profundo conhecedor dos modernos methodos pedagógicos, vem imprimindo àquele estabelecimento um cunho excepcional de organização e disciplina”. Em curto lapso de tempo soube "conquistar a estima e sympatia da sociedade montes-clarense” (GN, 776, 1931), "alliando a esses dotes de espírito, raros predicados 
de coração e de caracter”, além de ser “um espírito altamente competente e realisador" (GN, 870, 1933), "individualidade a quem tanto deve a Escola Normal de Montes Claros” (GN, 910, 1934). Dessa forma, em 1933, a sua transferência para o cargo de vice-reitor do Ginásio Mineiro, mesmo compreendida como perda para Montes Claros, foi reconhecida como "um justo premio ao esforço, dedicação e operosidade com que o dr. Floriano de Paula” (GN, 870, 1933) exercia suas atividades profissionais.

Já o professor Plínio Ribeiro dos Santos era um “illustrado clinico" (GN, 910, 1934) e "esforçado director” (GN, 893, 1935), enquanto o seu sucessor, José Raymundo Netto, era um "illustre educador" (GN, 893, 1933), “cultor das letras”, “moço de sólida cultura e aprimorados dotes intellectuaes, revelando-se um perfeito educador e um profundo conhecedor dos modernos methodos de ensino” (GN, 905, 1934). Era “pessoa de visão” (GN, 966, 1935), dispunha de “energia, operosidade e reconhecida capacidade de trabalho” ( $G N, 905,1934)$; era o "regente desta orchestra maviosa afinada no diapasão da ordem, no rythmo da disciplina, na cadência do methodo e sobretudo na melodia excelsa da instrucção sociabilizada”. E mais: era a "garantia plena e absoluta da victoria intellectual da exuberante juventude de Montes Claros” (GN, 966, 1935).

Ao corpo discente também foi lançado olhar positivo, sendo elogiados o empenho e a dedicação. Em 1923, ao falar do reinício das aulas após quatro anos de desativação da Escola Normal, a Gazeta do Norte destacou ser "motivo de real prazer ver-se a mocidade, pressurosa, dirigir-se à Escola, logo pela manhã, em busca de pão espiritual” (GN, 253, 1923). Assim, os alunos obtinham diplomas como "resultado de seus esforços” ( $G N, 608,1928)$ e "serão amanhã os homens de vossa terra". Ao falar especificamente das normalistas, o jornal as descreveu como jovens "dynamicas, confiantes e cheias de entusiasmo, em doce convivio de socialização e sociabilidade!...” (GN, 966, 1935).

Enfim, a Gazeta do Norte produziu e colocou em circulação um conjunto de imagens altamente positivas da Escola Normal. Entendendo com Baczko
(1985) que um sistema de representações traduz e legitima a ordem do grupo social que o produziu, consideramos que essas representações visavam legitimar a escola, obter a adesão dos cidadãos e mobilizar sua ação, fazer crer nos ideais de civilização e no futuro de progresso. Ainda tomando Baczko (1985) como referência, ao afirmar que qualquer sociedade, ao produzir um sistema simbólico também instala seus “guardiões”, consideramos que, em Montes Claros, os intelectuais ligados à Escola Normal e à Gazeta do Norte eram esses guardiões, que trabalhavam para produzir, alimentar e manter um conjunto de representações impulsionadoras da ação coletiva.

Para Baczko (1985), raramente os percursos imaginados se cumprem, porque as previsões têm limites e deficiências. Contudo, a defasagem entre a imaginação e as ações efetivamente realizadas pelos sujeitos sociais não anula as funções reais desses percursos imaginados, mas as coloca em realce. Isso porque, em qualquer conflito social grave, "as imagens exaltentes e magnificentes" dos objetivos a atingir e dos frutos da vitória procurada parecem ser condição de possibilidade da própria ação.

Raciocínio semelhante pode ser identificado em Chartier (1990, 2002), ao discutir a pertinência operatória do conceito de representação para tratar de objetos culturais. Para o autor, a distinção entre representação e representado pode ser pervertida pelas formas de teatralização da vida social, pela produção de mecanismos que tenham em vista fazer com que a identidade do ser não seja outra coisa senão a aparência da representação; isto é, que a coisa somente exista no signo que a exibe. E esse é um tipo de funcionamento que leva a crer que a aparência vale pelo real, pois a relação de representação é deturpada. Confundida pela ação da imaginação, a representação transforma-se em instrumento de poder e violência. Fazendo tomar o logro pela verdade, uma sociedade pode ostentar signos visíveis como provas de uma realidade que não o é (Chartier, 1990).

Afinal, "é nas ilusões que uma época alimenta a respeito de si própria que ela manifesta e esconde, ao mesmo tempo, a sua 'verdade', bem como o lugar 
que lhe cabe na 'lógica da história'” (Baczko, 1985, p. 303, ênfases do original). Ou seja, no processo de produção de representações, indivíduos ou grupos sociais podem produzir uma "aparência” capaz de impressionar a imaginação, de conferir legitimidade a determinados processos dados a ver, fazendo crer nos signos ostentados. Essas representações podem não ser a realidade, mas aquilo que os seus produtores pensam que é o real ou aquilo que gostariam que fosse.

Esse modo de compreensão leva-nos a pensar que as práticas “reais” desenvolvidas pela Escola Normal de Montes Claros podem não corresponder à imagem de sucesso propalada pela Gazeta do Norte. Os discursos jornalísticos podem ter construído uma aparência em que a imagem de sucesso tinha valor de realidade e visava impressionar. Por concordarmos com Baczko (1985) em que a imaginação é uma faculdade em cujo lume as paixões se acendem e para a qual se dirige a linguagem dos símbolos, consideramos natural que a Gazeta do Norte tenha trabalhado nesse campo e que tenha produzido e disseminado imagens grandiosas da realidade. Se o coração e os desejos do homem são o princípio que impulsiona as ações, também consideramos natural que o jornal tenha projetado um futuro de sucesso como forma de mobilizar as ações dos intelectuais e da comunidade local. E, independentemente de o sucesso da Escola Normal ter sido real ou fabricado pelo jornal, a força da palavra e a eloquência dos discursos fixaram imagens de sucesso que permaneceram no imaginário social de sucessivas gerações que a frequentaram.

A Gazeta do Norte trabalhou para fazer crer na Escola Normal como instituição importante e bemsucedida - fundada por montes-clarenses altruístas e desinteressados, dirigida e mantida por professores cultos, abnegados e laboriosos, frequentada por alunos dinâmicos e esforçados. Visando a atingir esse objetivo, entendemos a publicação de Termos de Visita e de Inspeção Técnica como estratégias utilizadas pelo jornal, por tornar públicos os julgamentos emitidos por pessoas socialmente legitimadas. E o peso dessas publicações estava localizado nos indivíduos que as emitiram. Mais do que "visitantes ilustres", os fiscais, inspetores e assistentes técnicos do ensino representavam a autoridade instituída.

A publicação desses julgamentos "legítimos" servia para dar credibilidade ao trabalho da escola, imprimir e reforçar uma imagem positiva. Ainda perseguindo o objetivo de impressionar a imaginação social, compreendemos as festas pomposas, as solenidades, as homenagens e as honrarias como peças montadas para dar a ver essa realidade. Elas ajudavam a construir uma imagem, mostrando determinadas facetas capazes de causar forte impressão. Até a descrição dos espaços guardava relação com essa intencionalidade, sendo representativa de um valor atribuído aos eventos realizados pela escola. Na solenidade de sua reinstalação, em 1923, “o amplo e elegante salão acha[va]-se ricamente ornamentado de flôres naturaes e galhardetes, ostentando-se artísticos jarrões, estheticamente distribuídos ao redor da mesa da presidência, vendo-se ao fundo o pavilhão nacional” (GN, 250, 1923).

Entendemos que, mais do que um ato de celebração, essas solenidades se constituíam como aparatos produzidos para impressionar, conferir credibilidade e distinção, estabelecer um lugar de poder e autoridade da Escola Normal. Como parte dessa encenação, para as solenidades eram convidadas as autoridades locais (o bispo, o juiz municipal, o presidente da Câmara, o prefeito etc.), que legitimavam a instituição e suas realizações. Por essa lógica, como paraninfos da escola foram convidados o bispo da arquidiocese (dom João Pimenta) e o político mais tradicional e conhecido da cidade (senador Camilo Prates).

Nesse processo de construção de um imaginário social, a Gazeta do Norte teve papel ativo, não apenas por produzir representações, mas, sobretudo, por colocá-las em circulação e ampliar o alcance das imagens e símbolos produzidos. O jornal fez circular diferentes representações produzidas pela própria Escola Normal, por visitantes "ilustres", inspetores etc., que confirmavam e davam a ver o seu valor. Essas representações constituíam-se como mecanismos de legitimação de suas práticas e de seu papel junto à comunidade.

Como as representações não são neutras, mas inscrevem-se no plano dos interesses de quem as 
produz, a Gazeta do Norte nem sempre apresentou uma imagem idealizada da realidade e, em determinadas ocasiões, caracterizou Montes Claros como uma cidade não civilizada. Quando a imaginação trabalhava e produzia o projeto de futuro, o jornal assumia uma posição idealista, que se alicerçava no desejo de construir a cidade como lugar desenvolvido e civilizado. Em outros momentos, quando os problemas pareciam ser maiores do que a capacidade de ação, o jornal assumia uma posição realista e estampava a insatisfação com as condições em que a educação se encontrava.

Por essa visão, quando o objetivo era denunciar o descuido da população, tecer críticas ao estado de abandono pelos poderes públicos e reivindicar investimentos públicos, a cidade apresentava-se em seu atraso e retrocesso, em sua condição de penúria, e a educação era vista como defeituosa e problemática. Ao apresentar facetas negativas da realidade, a intenção não era desqualificar a cidade, mas cobrar atitudes e ações capazes de impulsionar o sonho de desenvolvimento e civilização.

Por essa estratégia, que procurava ocultar ou dar a ver algumas facetas da realidade, em 1918, momento em que a Escola Normal havia sofrido uma interrupção de seu funcionamento, a Gazeta do Norte mostrou a cidade em sua condição de atraso e apontou o governo municipal como responsável. Nas palavras do jornal: "temos a vergonha e humilhante certeza de verificar o nosso retrocesso, o nosso atrazamento, sob tal ponto de vista, em relação àquela quadra de vida quasi primitiva” (GN, 25, 1918).

Em 1922, momento em que a Escola Normal ainda não havia restabelecido seu funcionamento, ao endereçar apelo a Raul Soares, novo presidente de Minas, o jornal reafirmou a situação de atraso: "pode-se dizer, sem temeridade, que o ensino público entre nós, pela força que vae sendo praticado, nenhum proveito tem trazido em bem da educação de nossos filhos" (GN, 218, 1922). Em função da inexistência de uma fiscalização eficiente e do desinteresse dos professores, a situação do ensino no estado, mas principalmente em nossa região, era de uma "verdadeira anarquia”.
As creancas vivem n'um completo estado de desamparo espiritual, quer em se tratando de instrucção propriamente dita, quer se tratando de formar os seus pequenos corações, fazendo brotar n'elles os bons sentimentos e o amor da pátria, a obediência a família e o conhecimento do cidadão. (GN, 218, 1922)

Em contraposição a esse estado de penúria, em 1926, quando a Escola Normal já havia sido restabelecida e equiparada às escolas oficiais mineiras, ao comemorar a chegada da ferrovia, a Gazeta do Norte considerou que Montes Claros havia conquistado um elemento fundamental de progresso. A inauguração da estação da Estrada de Ferro Central do Brasil era o acontecimento que integraria a cidade "no convívio com a civilização”. Para o jornal:

\footnotetext{
Montes Claros tem evoluído, tem sido objeto de admiração a quantos aqui chegam. O seu grao de progresso e adeantamento, tendo em vista a distancia que a separava dos grandes centros civilisados, é uma prova frizante de suas possibilidades, não grado todas as dificuldades que tinha a vencer para fazer-se notar daquelles que vem dirigindo os destinos do Estado. (GN, 469, 1926)
}

Esse posicionamento é revelador da forte presença da Escola Normal, dos conflitos que existiam no contexto local, das disputas por representação. Outro campo em que a dualidade foi identificada e a contradição encontrou lugar para manifestar-se foi o político. Apesar do vínculo com a Concentração Conservadora, a Gazeta do Norte afirmava ser um jornal apolítico - "temos agido, nos oito annos que contamos de existência, com a maior independência, fazendo justiça sempre aos homens de governo quando praticam actos que merecem a gratidão do povo” (GN, 419, 1926).

Dessa forma, no ano de 1928, em momento de "rigosijo intenso", ao congratular-se pela oficialização da Escola Normal, o jornal agradeceu ao presidente Antônio Carlos, que, "fiel aos seus princípios de 'governar dentro das normas das mais rigorosas justiças' conservou [os professores] em sua quase totalidade em suas cadeiras” (GN, 608, 1928, ênfase do original). 
Contudo, no ano de 1930, momento de disputa política, a Gazeta do Norte retomou a questão e teceu críticas ao "vendaval carlista de desrespeito aos direitos particulares e políticos dos cidadãos”, desrespeito que se manifestou na não nomeação de todos que nela vinham trabalhando, "realizando a mais comesinha justiça". Isso porque, "a par de algumas nomeações justas”, foram nomeadas "várias pessoas que nunca tiveram o menor trabalho com a mesma, preterindo antigos professores como Rady Gorky e dr Pedro Velloso" (GN, 703, 1930).

Ou seja, em relação às ações e posicionamentos assumidos pelo governo mineiro, dependendo dos interesses do jornal, o tom era de aceitação ou agradecimento; mas também poderia ser de críticas e cobranças, apontando-se o descaso do poder público e a injustiça cometida contra Montes Claros.

Por um processo semelhante, esses conflitos também foram identificados em relação à capacidade altruística dos montes-clarenses. Nos momentos de distinção e festejos, os intelectuais eram pessoas de espírito abnegado, que "há annos vem desinteressadamente prestando concurso efficiente para que se mantivesse aqui uma Escola Normal, capaz de ministrar instrucção, a essa zona Norte Mineira” (GN, $608,1928)$. No entanto, em virtude da dificuldade de preencher vagas no quadro docente, no ano de 1927 a Gazeta do Norte se pronunciou em tom acusatório, dirigindo cobranças e severas censuras aos montesclarenses. Em suas palavras: "causa pena, causa desillusão pelo futuro de nossa terra, esse interesseiro egoísmo dos nossos intellectuaes, negando-se a trabalhar pelo ensino". Para o jornal, muitos médicos, bacharéis, engenheiros e farmacêuticos não se dispunham a ocupar os cargos vagos de professor porque eram "filhos ingratos e imprestáveis à Mãe Cidade", "ingratos a terra em que nasceram ou que lhes vem o pão ao seu sustento” (GN, 552, 1927).

Por esse discurso, é relativizada a ideia de altruísmo e trabalho desinteressado. Afinal, os professores tinham interesses, moviam-se também por eles, e não apenas pela abnegação e desprendimento. O próprio fundador da Escola Normal teve seus interesses reve- lados pela Gazeta do Norte. Ao discutir uma situação de conflito vivida em 1925, o jornal destacou o apelo que o professor João de Andrade Câmara dirigiu a seus colegas, "para que ao menos a turma daquelle anno terminasse os exames e o curso" (GN, 703, 1930). Conforme informava o jornal, o professor João Câmara tinha filhas e sobrinhas matriculadas na turma de normalistas concluintes daquele ano e desejava que elas se formassem. Ou seja, o jornal não negava o tanto que o professor "se devotou à Escola"; contudo, indicava a existência de outros interesses pessoais e não altruísticos ligados à continuidade do funcionamento da escola.

\section{Considerações finais}

Conforme Baczko (1985), a passagem da cultura oral para a escrita e a implantação duradoura dos meios de comunicação de massa marcaram rupturas significativas na circulação das informações, por garantirem que um único emissor tivesse possibilidade de atingir simultaneamente uma ambiência enorme. E se, conforme o autor, a influência dos imaginários sobre as mentalidades depende dos meios que asseguram a sua difusão, no contexto montes-clarense a Gazeta do Norte, com publicações regulares de 1918 até 1962, ocupou um lugar diferenciado. Por ter sido o primeiro periódico a consolidar-se no ramo jornalístico, quando outros jornais já haviam sido instalados e desativados, por um longo período o jornal produziu representações e possibilitou sua circulação. Apesar de estar limitado por sua periodicidade semanal, o jornal tinha circulação em toda Região Norte mineira - condição que ampliava seu poder de interferência e afigurou-nos como dado importante na leitura da realidade local.

O jornal integrou o movimento local pela modernidade e conferiu visibilidade para ações de um grupo de intelectuais montes-clarenses que, no passado, projetaram um futuro para Montes Claros, sonharam um lugar civilizado, culto e moderno, desejaram que a cidade do sertão se aproximasse dos grandes centros civilizados. Tomando Baczko (1985) como referência, 
consideramos não ser possível discutir os limites ou deficiências de uma previsão. Por isso compreendemos que nada tira as funções reais dos percursos imaginados pelos montes-clarenses.

Mesmo dando a ver algumas mazelas e problemas, a Gazeta do Norte produziu imagens que exaltavam o valor dos intelectuais montes-clarenses, identificando-se nessas imagens. Por essa identificação escola-jornal, e o pertencimento do advogado José Thomaz de Oliveira a essas duas instâncias, era de se esperar que a Escola Normal não fosse desmerecida e desqualificada nas páginas do periódico. Para o proprietário-redator do jornal, produzir uma imagem negativa da Escola Normal era produzir uma imagem negativa de si mesmo. Desqualificar o trabalho dos professores da Escola era desqualificar a si mesmo como parte integrante desse corpo docente.

Os posicionamentos que o jornal assumiu, as facetas da realidade para as quais conferiu visibilidade ou que omitiu, as imagens que produziu e os significados/funções que lhes foram atribuídos constituem um complexo sistema de representações. E, por serem representações do mundo social, não podem ser compreendidas como verdades ou como produções neutras. Por estarem imbuídas de interesses e significações, as imagens e símbolos não são a realidade, mas a representam e fazem parte de um processo de informar e formar a opinião pública.

\section{Fontes documentais}

Gazeta do Norte. SARMENTO, Honor. Cartas Semanaes, n. 10, 7 set. 1918.

Gazeta do Norte, n. 25, 2 dez. 1918.

Gazeta do Norte, n. 26, 28 dez. 1918.

Gazeta do Norte, Grupo Escolar, n. 31, 1 fev. 1919.

Gazeta do Norte. ALTES. A instruç̧ão, n. 33, 15 fev. 1919.

Gazeta do Norte. SARMENTO, Honor. Cartas Semanaes, n. 44, 3 maio 1919.

Gazeta do Norte. Escola Normal, n. 67, 18 out. 1919.

Gazeta do Norte. CÂMARA, João de Andrade. Recenseamento, n. 110, 14 ago. 1920.

Gazeta do Norte. Cartas Semanaes, n. 134, 29 jan. 1921.
Gazeta do Norte. AFELINO. Instrucção publica - um appello ao novo governo, n. 218, 23 jul. 1922.

Gazeta do Norte. Escola Normal de Montes Claros, n. 245, 31 mar. 1923.

Gazeta do Norte. PEREIRA, Cícero. Escola Normal de Montes Claros, n. 245, 31 mar. 1923.

Gazeta do Norte. Escola Normal, n. 248, 21 abr. 1923.

Gazeta do Norte. Escola Normal, n. 249, 28 abr. 1923.

Gazeta do Norte. PEREIRA, Cícero. Escola Normal. Liga de Paes e Professores, n. 253, 26 maio 1923.

Gazeta do Norte. Uma bella iniciativa, n. 254, 2 jun. 1923.

Gazeta do Norte. Caixas escolares, n. 274, 20 out. 1923.

Gazeta do Norte. Início das aulas na Escola Normal, n. 249, 29 mar. 1924.

Gazeta do Norte. E. N. Mello Vianna: a sua equiparação às officiaes do Estado, n. 340, 27 dez. 1924.

Gazeta do Norte. Escolas Regionaes, n. 419, 6 fev. 1926.

Gazeta do Norte. O maior dia de Montes Claros, n. 469, 1 jul. 1926.

Gazeta do Norte. MORAES, Jazon de. Escola Normal Regional Norte, n. 547, 6 jul. 1927.

Gazeta do Norte. Seja útil à sua terra, n. 552, 23 jul. 1927.

Gazeta do Norte. E. Normal M. Vianna, n. 608, 25 fev. 1928.

Gazeta do Norte. Escola Normal de Montes Claros, n. 610, 5 maio 1928.

Gazeta do Norte, n. 655, 6 jan. 1929.

Gazeta do Norte. Pela Instrucção - Escola Normal, n. 663, 16 mar. 1929.

Gazeta do Norte. Montes Claros progride, n. 673, 25 abr. 1929.

Gazeta do Norte. Pela Instrucção - Escola Normal Official, n. 674, jul. 1929.

Gazeta do Norte. Façanhas do Liberalismo Protestante, n. 703, 4 jan. 1930.

Gazeta do Norte. Pela Instrucção - Escola Normal, n. 754, 4 abr. 1931.

Gazeta do Norte. Dr. Floriano de Paula, n. 776, 5 jul. 1931.

Gazeta do Norte. Escola Nova, n. 868, 24 jun. 1933.

Gazeta do Norte. Dr. Floriano de Paula, n. 870, 8 jul. 1933.

Gazeta do Norte. Commentarios, n. 871, 15 jul. 1933.

Gazeta do Norte. Pela instrucção - Escola Normal Official, n. 893, 16 dez. 1933.

Gazeta do Norte. Pela instrucção - Escola Normal Official, n. 905, 17 mar. 1934 
Gazeta do Norte. RIBEIRO, Plínio. Discurso pronunciado pelo illustrado clinico dr. Plínio Ribeiro, n. 910, 2 abr. 1934.

Gazeta do Norte. CONTE, Alberto. Por que a Escola Nova é uma revolução pedagógica, n. 912, 5 maio 1934.

Gazeta do Norte. MELLO, Conceição Freitas Rocha. Embaixada acadêmica que nos visita, n. 922, 21 jul. 1934.

Gazeta do Norte. RAYMUNDO NETTO, José. Pela Instrucção. Normalistas de 1934, n. 946, 5 jan. 1935.

Gazeta do Norte. CARVALHO, Arnaldo de. A instrucção no Norte de Minas, n. 966, 1 jun. 1935.

Gazeta do Norte. RAYMUNDO NETTO, José. Escola Normal Official, n. 972, 13 jul. 1935.

Gazeta do Norte. Pela instrucção: Escola Normal Official, n. 975, 3 ago. 1935.

Jornal Montes Claros. MARTINS, Olyntho. Escola Normal "Norte Mineira” - As festas de encerramento do anno letivo, ano I, n. 29, 23 nov. 1916.

MINAS GERAIS. Revista do Ensino: Órgão Oficial da Inspetoria da Instrução, Belo Horizonte, ano I, n. 1, 8 mar. 1925.

O Operário, n. 105, 1932. (Transcrito da Revista Minas Econômica.)

\section{Referências bibliográficas}

BACZKO, Bronislaw. Imaginação social. In: Enciclopédia Einaudi. ed. portuguesa, v. 5: Antropos-Homen. Lisboa: Imprensa Nacional-Casa da Moeda, 1985. p. 296-332.

BARROS, José D’Assunção. O campo da história: especialidades e abordagens. Petrópolis: Vozes, 2004.

CERTEAU, Michel de. A invenção do cotidiano: artes de fazer. 4. ed. v. 1. Trad. Ephraim Ferreira Alves. Petrópolis: Vozes, 1999.

CHARTIER, Roger. História cultural: entre práticas e representações. Trad. Maria Manuela Galhardo. Rio de Janeiro: Berthand do Brasil, 1990.

Cultura escrita, literatura e história: conversas de Roger Chartier com Carlos Aguirre Anaya, Jesús Anaya Rosique, Daniel Goldin e Antonio Saborit. Trad. Ernani Rosa. Porto Alegre: Artmed, 2001.
. À beira da falésia: história entre certezas e inquietudes. Trad. Patrícia Chittoni Ramos. Porto Alegre: Editora da Universidade/UFRGS, 2002.

LE GOFF, Jacques. Historia e memória. 5. ed. Trad. Irene Ferreira, Bernardo Leitão e Suzana Ferreira Borges. Campinas: Editora da UNICAMP, 2003.

NASCIMENTO, Milton Meira do. Opinião pública e revolução, aspectos do discurso político na França revolucionária. São Paulo: Nova Stella/EDUSP, 1989.

PAULA, Hermes Augusto de. Montes Claros: sua história, sua gente e seus costumes Montes Claros: Unimontes Editora, 2007. (Ed. original 1957. Coleção Sesquicentenária, v. 1.)

VIANNA, Urbino. Monographia do município de Montes Claros: breves apontamentos históricos, geographicos e descriptivos. Belo Horizonte: Imprensa Official do Estado de Minas Gerais, 1916.

GEISA MAGELA VELOSO, doutora em educação pela Universidade Federal de Minas Gerais (UFMG), é professora do Centro de Ciências Humanas da Universidade Estadual de Montes Claros (UNIMONTES), onde coordena o grupo de estudos e pesquisa em Educação e Linguagem. Publicações recentes: em coautoria com SILVA, Márcio Antônio da; MARTINS, Maria Nailde Ramalho; LOPES, Helda Maria Henriques Rodrigues. Programa de apoio às inovações escolares: uma proposta para descentralização da gestão escolar (In: FONSECA, Marília; OLIVEIRA, João Ferreira de; TOLCHI, Mirza Seabra. Escolas gerenciadas: planos de desenvolvimento e projetos político-pedagógicos em debate. Goiânia: Editora da Universidade Católica de Brasília, 2004); Cotas na universidade pública: direito ou privilégio? (In: REUNIÃO ANUALDAANPEd, 28., Caxambu, 2005. Anais... Caxambu:ANPEd, 2005.1 CD-ROM). Pesquisas em andamento: "História da alfabetização em Montes Claros: dos processos sintéticos ao uso do método global (1930-1970)” e “Alfabetizar letrando e construindo relações matemáticas”.E-mail: velosogeisa@gmail.com

Recebido em março de 2009 Aprovado em agosto de 2009 
contribute to enrich the debate on the limits and possibilities of teacher research.

Key words: educational research; primary education teachers; evaluation.

\section{La pesquisa del profesor de la} educación básica en análisis El texto discute la pesquisa del profesor con autores que ven en ella alguna posibilidad de ocurrir. Entre los autores trabajados, se destacan : Stenhouse, Elliott, Huberman, Geraldi, Fiorentini, Cochran-Smith, Lytle, Anderson, Herr, André Lüdke, Cruz, Zeichner, Diniz-Pereira, Nofke, Tardif y Zourhlal. Para servir de instrumento a la pesquisa, fueron seleccionados dos trabajos de profesores que fueron presentados en el XII Encontro Nacional de Didática e Prática de Ensino (ENDIPE, 2004) y otros dos en el II Seminário Internacional de Pesquisa em Educação Matemática (SIPEM, 2003). Los cuatro textos fueron enviados a 12 jueces, escogidos en diferentes instancias, entre profesionales bien preparados en sus respectivas áreas de formación, con una gran experiencia de pesquisa e intensa producción, además de interesados y sensibilizados con la formación de profesores, inclusive lo referente a su pesquisa. A partir de los pareceres de esos evaluadores, son presentados algunos resultados teóricos metodológicos y prácticos que pueden enriquecer el debate sobre los límites y posibilidades de la pesquisa de los profesores.

Palabras claves: pesquisa educacional; profesor de la educación básica; juzgamiento.

Gilberto Luiz Alves e Carla Villamaina Centeno

A produção de manuais didáticos de história do Brasil: remontando às origens (1838-1889)
O artigo decorre de um programa de pesquisa que investiga o papel dos instrumentos do trabalho didático na relação educativa. Elege como foco o discurso dos manuais didáticos de história do Brasil e, para aprofundar a análise do conteúdo, procura apreender as interpretações acerca da Guerra da Tríplice Aliança (1864-1870). Prioriza manuais didáticos pioneiros, produzidos no período imperial, a exemplo de Lições de história do Brazil, de Joaquim Manuel de Macedo, um dos principais compêndios da área no Colégio Pedro II. Esses manuais, quanto à concepção pedagógica e à forma de organização, comportavam incipiente simplificação e objetivação do trabalho didático que denotavam os primeiros indícios de uma organização técnica de base manufatureira.

Palavras-chave: história da educação; trabalho didático; manuais didáticos; história do Brasil; Guerra da Tríplice Aliança.

\section{The production of textbooks on the} history of Brazil: returning to the origins (1838-1889)

This article derives from a research programme investigating the role of teaching instruments in the educational relation. It selects as its focus the discourse of textbooks on the history of Brazil and, to sharpen its analysis of the content, it seeks to apprehend the interpretations of the War of the Triple Alliance (1864-1870). It prioritizes pioneering textbooks, produced in the imperial period, following the example of Lessons on the history of Brazil, by Joaquim Manuel de Macedo, one of the most important works on the subject used at the Pedro II College. With regard to their pedagogical conception and form of organization, these textbooks revealed an incipient simplification and objectification of educational work that denoted the first signs of technical organization of a manufacturing base.
Key words: history of education; educational work; textbooks; history of Brazil; War of the Triple Alliance.

La producción de manuales didácticos de historia de Brasil: remontando a los orígenes (18381889)

El presente trabajo resulta de un programa de investigación que trata del papel de los instrumentos de trabajo didáctico en la relación educativa. Elige como foco el discurso de los manuales didácticos de historia de Brasil y, para profundizar el análisis del contenido, busca aprehender las interpretaciones respecto a la Guerra de la Triple Alianza (1864-1870). Prioriza manuales didácticos pioneros, producidos en el período imperial, a ejemplo de Lições de história do Brasil, de Joaquim Manuel de Macedo, uno de los principales compendios del área en el Colégio Pedro II. Esos manuales, en cuanto a la concepción pedagógica y a la forma de organización, presentaban incipiente simplificación y objetivación del trabajo didáctico, que denotaban los primeros rasgos de una organización técnica de base manufacturera.

Palabras claves: historia de la educación; trabajo didáctico; manuales didácticos; historia de Brasil; Guerra de la Triple Alianza.

Geisa Magela Veloso

Imprensa e Escola Normal: representações de progresso e civilização na produção de um imaginário social - 1918-1938 Tomando elementos da história de Montes Claros, no estado de Minas Gerais, como referência, discute-se a utilização dos conceitos de representação, apropriação e prática (Chartier, 1990, 2001, 2002) e de imaginário social (Baczko, 1985), no contexto da história cultural. Confere-se visibilida- 
de a publicações da Gazeta do Norte, jornal que assumiu a missão de educar os montes-clarenses, elegendo a Escola Normal de Montes Claros como referência e inspiração para esse empreendimento. Visando seu propósito educativo e considerando os conteúdos em circulação, o jornal produziu representações positivas da escola e das práticas escolares, colocando a educação como eixo de desenvolvimento e progresso. Tais representações, imbuídas de interesses e significações, não são a realidade, mas integraram o processo de informar e formar a opinião pública e contribuíram para consolidar a Escola Normal e mobilizar ações da população local.

Palavras-chave: imaginário social; representações e práticas; apropriação; imprensa.

The press and the Normal School: representations of progress and civilization in the production of the social imagination - 1918-1938

Taking elements from the history of Montes Claros, in the State of Minas Gerais, Brazil, as reference, we discuss the use of the concepts of representation, appropriation and practice (Chartier, 1990, 2001, 2002) and of social imagination (Baczko, 1985), in the context of cultural history. We make use of reports published in the Gazeta do Norte, a newspaper which adopted the mission of educating the population of Montes Claros, choosing the "Escola Normal" (Normal School) as a reference and inspiration for this undertaking. Taking into consideration its educational purpose and the contents published, this newspaper produced positive representations of the school and its practices, situating education as the axis of development and progress. Such representations, full of interest and meanings, are not reality but integrated the process of informing and forming public opinion and contributed to consolidate the
Normal School and mobilize actions by the local population.

Key words: social imagination; representations and practices; appropriation; press.

Prensa y Escuela Normal: representaciones de progreso y civilización en la producción de un imaginario social

Tomando elementos de la historia de Montes Claros, en el estado de Minas Gerais, como referencia, se discute la utilización de los conceptos de representación, apropiación y práctica (Chartier, 1990, 2001, 2002) y del imaginario social (Baczko, 1985), en el contexto de la historia cultural. Se confiere visibilidad a las publicaciones de la Gazeta do Norte, periódico que asumió la misión de educar a los montes-clarenses, eligiendo a la Escuela Normal de Montes Claros como referencia e inspiración para este emprendimiento. Apuntando su propósito educativo y considerando los contenidos en circulación, el periódico produjo representaciones positivas de la escuela y de las prácticas escolares, colocando la educación como eje del desarrollo y progreso. Tales representaciones, llenas de intereses y significados, no son la realidad, sin embargo integraron el proceso de informar y formar la opinión pública y contribuyeron para consolidar la Escuela Normal y movilizar acciones de la populación local.

Palabras claves: imaginario social; representaciones y prácticas; apropiación; prensa.

Josimeire M. Julio e Arnaldo M. Vaz

Representações de masculinidades latentes em aulas de física do ensino médio

O estudo caracteriza aspectos latentes de masculinidades que trazem implicações para a aprendizagem individual e coletiva em uma turma de ensino médio. Aulas de física de uma turma de primeira série do ensino médio foram acompanhadas ao longo de um ano. A microanálise de uma sequência de seis aulas - gravadas em áudio e em vídeo - envolvendo uma atividade que simula o trabalho de uma comunidade científica caracteriza as interações predominantes entre os rapazes. As masculinidades destacadas mobilizamse em torno do estímulo diante de situações desafiadoras e de competição, da curiosidade pelo fenômeno investigado, do desafio às regras estabelecidas na condução da atividade. Entre as implicações do estudo, destaca-se a necessidade de levar em consideração manifestações de masculinidades que possam comprometer o desenvolvimento das atividades em sala de aula e o funcionamento dos grupos de aprendizagem.

Palavras-chave: representações de masculinidade; ensino de física; atividades investigativas.

Representations of latent masculinity in secondary education classes of Physics

The study characterizes latent aspects of masculinity that present implications for individual and collective learning in a class of secondary education. Physics classes of first year students were observed for one academic year. A microanalysis of a thematic unitrecorded on audio and video - in an activity that simulates the work of a scientific community characterizes the predominant interactions between the boys. Some manifestations of masculinity were predominant among boys in classroom activities that were challenging and competitive and others, in which rules had to be observed. Results suggest the kind of circumstances in which such masculinities might be manifested jeopardizing the development of classroom activities and the dynamics of learning groups. 